This is the final peer-reviewed accepted manuscript of:

"Disruption of redox homeostasis and carcinogen metabolizing enzymes changes by administration of vitamin E to rats".

VIVARELLI, FABIO; CANISTRO, DONATELLA; FRANCHI, PAOLA; SAPONE, ANDREA; VORNOLI, ANDREA; Della Croce, C; Longo, V; LUCARINI, MARCO; PAOLINI, MORENO.

Life Sciences, 145 (2016) 166-173.

The final published version is available online at: https://doi.org/10.1016/J.LFS.2015.12.033

Rights / License:

The terms and conditions for the reuse of this version of the manuscript are specified in the publishing policy. For all terms of use and more information see the publisher's website.

This item was downloaded from IRIS Università di Bologna (https://cris.unibo.it/)

When citing, please refer to the published version. 


\title{
Disruption of redox homeostasis and carcinogen metabolizing enzymes changes by administration of vitamin $\mathrm{E}$ to rats
}

\author{
Fabio Vivarelli a, ${ }^{\mathrm{a}, 1}$, Donatella Canistro ${ }^{\mathrm{a}, *, 1}$, Paola Franchi ${ }^{\mathrm{b}}$, Andrea Sapone ${ }^{\mathrm{a}}$, Andrea Vornoli ${ }^{\mathrm{c}}$, \\ Clara Della Croce ${ }^{\mathrm{d}}$, Vincenzo Longo ${ }^{\mathrm{d}}$, Marco Lucarini ${ }^{\mathrm{b}}$, Moreno Paolini ${ }^{\text {a }}$ \\ ${ }^{a}$ Molecular and Toxicology Unit, Department of Pharmacy and Biotechnology, Alma-Mater Studiorum, University of Bologna, via Irnerio 48, 40126 Bologna, Italy \\ b Department of Chemistry “G. Ciamician", Alma-Mater Studiorum, University of Bologna, Via Selmi 2, 40126 Bologna, Italy \\ ${ }^{\mathrm{c}}$ Institute of Clinical Physiology, CNR, via Moruzzi 1, 56124 Pisa, Italy \\ d Institute of Agricultural Biology and Biotechnology, CNR, via Moruzzi 1, 56124 Pisa, Italy
}

\section{A B S T R A C T}

Aims: A large meta-analysis of randomized clinical trials has seriously questioned chemoprevention based on vitamins including vitamin $\mathrm{E}(\mathrm{VE})$, and an increased risk for cancer among long-term users was actually seen. However, the mechanism underlying these findings still remain unknown. To clarify the mechanism, in an in vivo model we studied the putative disruption of redox homeostasis and the perturbation of carcinogen metabolizing enzymes determined by VE.

Main methods: Male Sprague-Dawley rats were treated ip with either 100 or $200 \mathrm{mg} / \mathrm{kg}$ b.w. daily for 7 or 14 consecutive days. Controls received vehicle only. Cytochrome P450 (CYP) content, CYP-reductase, CYP-linked monooxygenases, as well as phase-II and the antioxidant enzymes catalase and $\mathrm{NAD}(\mathrm{P}) \mathrm{H}$ :quinone reductase were investigated in both liver and kidney. Free radical species in tissue subcellular preparations were measured by electronic paramagnetic resonance (EPR) spectroscopy coupled to a radical probe technique.

Key findings: No substantial changes of hepatic xenobiotic metabolism enzymes were determined by VE. Conversely, a powerful booster effect of various renal phase-I carcinogen bioactivating enzymes at both dosages and observational times was recorded. While no relevant changes of post-oxidative phase-II reactions were found in the liver, a significant inactivating effect was caused by VE in renal tissues. Antioxidant enzymes were found mainly downregulated by the treatment. In the kidney, a marked free radical over-generation linked to CYP induction was observed.

Significance: This study proved that VE acts as a co-carcinogen and pro-oxidant agent. Such epigenetic mechanisms may contribute to explain the harmful outcomes observed in humans.

\section{Introduction}

Vitamin $\mathrm{E}$ (VE) is a term that encompasses a group of potent, lipidsoluble, chain-breaking antioxidants composed of a group of eight naturally occurring tocopherols and tocotrienols of subtypes $\alpha, \beta$, $\gamma$, and $\delta$. Of these, $\alpha$-tocopherol subunit seems to be the most abundant, biologically active, and it is preferentially absorbed and

Abbreviations: APND, aminopyrine N-demethylase; b.w., body weight; CAT, catalase; CEHC, carboxyethylhydroxychromane; CYP, cytochrome P-450; CYP-red, NADPH-(CYP)c-reductase; DCPIP, dichlorophenolindophenol; EPR, electronic paramagnetic resonance; EROD, ethoxyresorufin O-deethylase; ECOD, ethoxycoumarin O-deethylase; GST, glutathione S-transferase; ip, intraperitoneal; MROD, methoxyresorufin O-demethylase; NQO1, $\mathrm{NAD}(\mathrm{P}) \mathrm{H}$ :quinone reductase; $\mathrm{p}-\mathrm{NFH}$, p-nitrophenol hydroxylase; $\mathrm{PROD}$, pentoxyresorufin O-dealkylase; UDPGT, UDP-glucuronosyl transferase; VE, vitamin E.

* Corresponding authors at: Department of Pharmacy and Biotechnology, Alma Mater Studiorum, University of Bologna, via Irnerio 48, 40126 Bologna, Italy.

E-mail addresses: fabio.vivarelli3@unibo.it (F. Vivarelli), donatella.canistro@unibo.it (D. Canistro).

1 These authors contributed equally to this work. accumulated in humans [1,2]. VE is absorbed together with lipids, then transported to the liver and this process is similar for all forms of vitamin E. $\omega$-Hydroxylation of the tocopherol phytyl side-chain by cytochrome P450 (CYP) play a major role in regulating tissue tocopherol concentrations, followed by stepwise removal carbon moieties then converted to the carboxyethyl-hydroxychromane (CEHC) metabolite that in turn is largely excreted in the urine after glucuronide conjugation [3].

Since its discovery and isolation, VE has been considered a "safe" agent [4], and its antioxidant activity has persuaded many scientists to further investigate its abilities in preventing chronic diseases, especially those believed to have oxidative components such as cardiovascular disorders, atherosclerosis, and cancer [5-9]. Although the relationship between VE supplementation and cancer risk has been investigated in many epidemiological studies and clinical trials, results are conflicting and its putative protective role is now under debate more then ever.

The Nutritional Prevention of Cancer (NPC) study and the AlphaTocopherol, Beta-Carotene Cancer Prevention (ATBC) study showed a 
reduction in prostate cancer risk of respectively $63 \%$ and $32 \%$ after selenized yeast and $\alpha$-Tocopherol supplementation [10,11]. In addition, a randomized-controlled trial reported that $\mathrm{VE}$, in combination with selenium and $\beta$-carotene, reduced the overall cancer mortality [12], and these observations were supported by epidemiologic data [13,14]. However, several subsequent trials and a meta-analysis largely rejected these results. Many of these studies pointed out that VE was neither beneficial nor harmful, not supporting the routine use of VE [15-19] while more recent studies show how VE taken at high doses (far exceeding the intake derived from dietary sources) revealed a dosedependent relationship between VE supplementation and all-cause mortality [20] as well as representing a hazard for several cancer forms including prostate, non-melanoma skin cancer, colorectal cancer and lung adenocarcinoma [21-24]. These outcomes have once again taken the role of VE to the heart of scientific debate, particularly considering that more and more people take large amounts of VE for its alleged therapeutic or prophylactic value [21]. However, the underlying mechanism of the observed detrimental effects is still unknown.

Evidence from both in vitro and in vivo models suggested that VE might increase the hepatic production of cytochrome P450 (CYP). CYP2C11, and several CYP1 and CYP2 family members were found to be up-regulated in VE-supplemented rats [22-24]. Such induction phenomenon may increase the biotransformation of ubiquitous precarcinogens (co-carcinogenicity) and generate an over-production of oxygen centred radicals [25-32].

In an in vivo model we investigated whether the harmful outcomes of VE are mediated by the perturbation of carcinogen metabolizing enzymes and by disruption of the redox homeostasis.

\section{Materials and methods}

\subsection{Chemicals}

Acetic acid (PubChem CID:176), aminopyrine (PubChem CID:6009), bovine serum albumin (PubChem CID:16132389), dichlorophenolindophenol (PubChem CID:13726) (DCPIP), epinephrine (PubChem CID:5816), ethoxycoumarin (PubChem CID:35703), Folin-Ciocalteu reagent, glycerol (PubChem CID:753) from Sigma-Aldrich, glucose 6-phosphate (PubChem CID:5958) and glucose 6-phosphate dehydrogenase from Roche Diagnostic; L-glutathione oxidized (PubChem CID:71308714), L-glutathione reduced (PubChem CID:745), methanol (PubChem CID:5958), methoxyresorufin (PubChem CID:119220), Nicotinamide adenine dinucleotide phosphate in oxidized (PubChem CID:5886) and reduced form (PubChem CID:5886) (NADP + and NADPH), p-nitrophenol (PubChem CID:980), pentoxyresorufin (PubChem CID:107683), perchloric acid (PubChem CID:24247), resorufin (PubChem CID:69462), sodium dithionite (PubChem CID:24489), trichloroacetic acid (PubChem CID:6421), Triton X-100 (PubChem CID:5590), Trizma (PubChem CID:16218782), umbelliferone (PubChem CID:4412127), 1chloro-2,4-dinitrobenzene (PubChem CID:6), 1-naphthol (PubChem CID:7005), 7-ethoxyresorufin (PubChem CID:3294) from SigmaAldrich. Vitamin E in the form of DL-all-rac $\alpha$-Tocopherol (PubChem CID: 2116).

All others chemicals were highest purity commercially available.

\subsection{Animal treatment}

Male Sprague-Dawley rats (Harlan Laboratories S.r.l.), weighing 150-180 g, were housed under controlled condition (12 h light-dark cycle, $22{ }^{\circ} \mathrm{C}, 60 \%$ humidity).

All the experimental procedures were carried out in conformity with protocols endorsed by the National Academy of Science guidelines and in accordance with EU Directive 2010/63/EU for animal experiments. The protocol was approved by the Committee on the Ethics of Animal Experiments of the University of Bologna. All efforts were made to minimize suffering. Animals were fed a rodent chow and had tap water ad libitum. After 1-week acclimatization period, all animals were randomly divided into six experimental units of six animals each. VE was dissolved in corn oil and administered intraperitoneally (ip) at doses of $100 \mathrm{mg} / \mathrm{kg}$ or $200 \mathrm{mg} / \mathrm{kg}$ b.w. daily for 7 or 14 consecutive days. Animals assigned to control groups received ip an equal volume of vehicle (corn oil).

\subsection{Tissue collection and subcellular fraction preparation}

Rats were fasted $16 \mathrm{~h}$ prior sacrifice, which occurred $24 \mathrm{~h}$ after the last treatment. They were sacrificed by decapitation, in accordance with approved Ministerial procedures appropriate to the species. Liver and kidney were rapidly removed and processed separately. After extensive mincing with a pair of scissors, the tissue was homogenized in sucrose with IKA Ultra-Turrax homogenizer. The S9 fraction $(9000 \times g)$ from liver was then prepared [33]. The post-mitochondrial supernatant so obtained was then centrifuged for $60 \mathrm{~min}$ at 105,000 $\times \mathrm{g}$, after which the cytosolic fraction (supernatant) was collected and immediately frozen in liquid nitrogen and stored at $-80^{\circ} \mathrm{C}$. The pellet resuspended in $0.1 \mathrm{M} \mathrm{K}_{2} \mathrm{P}_{2} \mathrm{O}_{7}, 1 \mathrm{mM}$ EDTA buffer ( $\mathrm{pH}$ 7.4) was centrifuged again for $60 \mathrm{~min}$ at $105,000 \times \mathrm{g}$ to give the final fraction. Washed microsomes were then resuspended with an hand-driven Potter Elvehjem homogenizer in a $10 \mathrm{mM}$ Tris-HCl buffer ( $\mathrm{pH} 7.4$ ) containing $1 \mathrm{mM}$ EDTA and 20\% ( $v / v)$ glycerol; fractions were immediately frozen in liquid nitrogen and stored at $-80^{\circ} \mathrm{C}$ prior to use.

\subsection{Haematological and serum biochemical analyses}

Blood samples were collected from each animal in both heparinized and non-heparinized tubes. Using a table top centrifuge to obtain plasma, samples collected in heparinised tubes were centrifuged for $15 \mathrm{~min}$ at $2000 \mathrm{rpm}$, while samples saved in non-heparinised tubes were centrifuged at $1500 \mathrm{rpm}$ for $10 \mathrm{~min}$ after complete coagulation, to obtain serum. Biochemistry and haematology were assessed by Department of Veterinary Medical Science, School of Agriculture and Veterinary Medicine, Alma Mater Studiorum University of Bologna.

\subsection{Protein concentration}

Protein concentration was determined according to the method described by Lowry et al. [34] as revised by Bailey [35], using bovine serum albumin as standard and diluting microsomes 200 times and cytosol 1000 times to provide a suitable protein concentration.

\subsection{Phase I enzymes}

\subsubsection{Cytochrome P450 (CYP) content}

CYP content was determined by a differential spectrophotometric assay using the Omura and Sato method [36]. CYP (0.5 ml of microsomes, $4.5 \mathrm{ml}$ of $0.05 \mathrm{M}$ Tris- $\mathrm{HCl}$ buffer $\mathrm{pH} 7.6$ and $10 \mathrm{mM}$ EDTA) was measured by examining the absorbance difference (between 450 and $490 \mathrm{~nm}$ ) of differential spectra, obtained between CYP that is reduced and linked to $\mathrm{CO}$, with respect to the free reduced form $\left(\varepsilon=91 \mathrm{mM}^{-1} \mathrm{~cm}^{-1}\right)$.

\subsubsection{NADPH-(CYP)-c-reductase (CYP-red)}

The analytical method is based on the determination of the reduction rate of cytochrome $c$ at $550 \mathrm{~nm}\left(\varepsilon=19.1 \mathrm{mM}^{-1} \mathrm{~cm}^{-1}\right)$, according to previously defined procedures [37]. Incubation mixture contained $1.6 \mathrm{ml}$ of $0.05 \mathrm{M}$ Tris- $\mathrm{HCl}$ buffer ( $\mathrm{pH} 7.7$ ) with $0.1 \mathrm{mM}$ EDTA $+0.5 \mathrm{mg}$ cytochrome $\mathrm{c}+0.2 \mathrm{ml}$ of microsomes. Reaction starts with the addiction of $0.2 \mathrm{ml} \mathrm{NADPH}$. The specific reaction was read at $550 \mathrm{~nm}$ against buffer plus cytochrome c [38]. 
Table 1

Expression of cyp-linked monooxygenase in hepatic subcellular fraction from VE treated rats.

\begin{tabular}{|c|c|c|c|c|c|}
\hline \multirow[t]{2}{*}{ Parameters } & \multirow[t]{2}{*}{ Controls } & \multicolumn{2}{|c|}{ Treatment (seven days) } & \multicolumn{2}{|c|}{ Treatment (fourteen days) } \\
\hline & & 100 mg/kg b.w. & $200 \mathrm{mg} / \mathrm{kg}$ b.w. & 100 mg/kg b.w. & $200 \mathrm{mg} / \mathrm{kg}$ b.w. \\
\hline Cytochrome P450 $\left(\mathrm{nmol} \times \mathrm{mg}^{-1}\right)$ & $0.39 \pm 0.03$ & $0.37 \pm 0.02^{*}$ & $0.44 \pm 0.03^{* *}$ & $0.35 \pm 0.01^{* *}$ & $0.39 \pm 0.02$ \\
\hline NADPH-cytochrome $(\mathrm{P} 450)$ reductase $\left(\mathrm{nmol} \times \mathrm{mg}^{-1} \times \min ^{-1}\right)$ & $21.05 \pm 1.56$ & $21.90 \pm 1.38$ & $19.10 \pm 1.67$ & $17.04 \pm 1.67^{* *}$ & $21.29 \pm 1.57$ \\
\hline Aminopyrine $N$-demethylase $\left(\mathrm{nmol} \times \mathrm{mg}^{-1} \times \mathrm{min}^{-1}\right)(\mathrm{CYP} 3 \mathrm{~A} 1 / 2)$ & $27.01 \pm 1.88$ & $30.15 \pm 3.56$ & $30.00 \pm 3.51$ & $30.14 \pm 1.93^{*}$ & $24.14 \pm 1.22^{* *}$ \\
\hline p-Nitrophenol hydroxylase $\left(\mathrm{nmol} \times \mathrm{mg}^{-1} \times \mathrm{min}^{-1}\right)($ CYP2E1) & $0.39 \pm 0.01$ & $0.39 \pm 0.01$ & $0.42 \pm 0.02^{* *}$ & $0.37 \pm 0.01^{* *}$ & $0.41 \pm 0.01^{* *}$ \\
\hline Ethoxycoumarin $O$-deethylase $\left(\mathrm{pmol} \times \mathrm{mg}^{-1} \times \min ^{-1}\right)$ & $0.54 \pm 0.01$ & $0.56 \pm 0.01^{*}$ & $0.50 \pm 0.01^{* *}$ & $0.53 \pm 0.01$ & $0.56 \pm 0.01^{*}$ \\
\hline Pentoxyresorufin $O$-dealkylase $\left(\mathrm{pmol} \times \mathrm{mg}^{-1} \times \mathrm{min}^{-1}\right)(\mathrm{CYP} 2 \mathrm{~B} 1 / 2)$ & $10.48 \pm 0.48$ & $12.50 \pm 0.43^{*}$ & $14.35 \pm 1.12^{* *}$ & $10.62 \pm 1.26$ & $11.48 \pm 0.60$ \\
\hline Ethoxyresorufin 0 -deethylase $\left(\mathrm{pmol} \times \mathrm{mg}^{-1} \times \mathrm{min}^{-1}\right)(\mathrm{CYP} 1 \mathrm{~A} 1)$ & $28.13 \pm 2.45$ & $19.77 \pm 0.70^{* *}$ & $22.23 \pm 1.81^{* *}$ & $19.58 \pm 0.84^{* *}$ & $19.04 \pm 1.30^{* *}$ \\
\hline Methoxyresorufin $O$-demethylase $\left(\mathrm{pmol} \times \mathrm{mg}^{-1} \times \mathrm{min}^{-1}\right)(\mathrm{CYP} 1 \mathrm{~A} 2)$ & $24.64 \pm 1.12$ & $22.48 \pm 1.19$ & $21.64 \pm 1.86^{*}$ & $20.24 \pm 0.82^{* *}$ & $17.11 \pm 1.20^{* *}$ \\
\hline
\end{tabular}

Each value represents the mean \pm S.D. of six independent experiments on six rats. See Section 2 for details and experimental procedures.

Mean values were significantly different compared with the control groups (Wilcoxon's rank method): ${ }^{*} \mathrm{p}<0.05,{ }^{* *} \mathrm{p}<0.01$.

\subsubsection{Aminopyrine $N$-demethylase (APND)}

Activity was determined by quantification of $\mathrm{CH}_{2} \mathrm{O}$ release, according to Mazel [39]. The total incubation volume was $3 \mathrm{ml}$, composed of $0.5 \mathrm{ml}$ of water solution of $50 \mathrm{mM}$ aminopyrine and $25 \mathrm{mM} \mathrm{MgCl}_{2}$, $1.48 \mathrm{ml}$ of $0.60 \mathrm{mM} \mathrm{NADP}+, 3.33 \mathrm{mM}$ G6P in $50 \mathrm{mM}$ Tris-HCl buffer (pH 7.4), $0.02 \mathrm{ml} \mathrm{G6PDH}(0.93 \mathrm{U} / \mathrm{ml})$ and $0.125 \mathrm{ml}$ of sample. After 5 min of incubation at $37^{\circ} \mathrm{C}$, the yellow colour developed by the reaction of the released of $\mathrm{CH}_{2} \mathrm{O}$ with the Nash reagent was read at $412 \mathrm{~nm}$, and the molar absorptivity of 8000 used for calculation [40].

\subsection{4. p-Nitrophenol hydroxylase ( $p$-NFI)}

Activity was determined in a final volume of $2 \mathrm{ml}: 2 \mathrm{mM}$ nitrophenol in $50 \mathrm{mM}$ Tris- $\mathrm{HCl}$ buffer ( $\mathrm{pH} 7.4$ ), $5 \mathrm{mM} \mathrm{MgCl}_{2}$, and a NADPH-generating system consisting of $0.4 \mathrm{mM} \mathrm{NADP}+, 30 \mathrm{mM}$ isocytrate, $0.2 \mathrm{U}$ of isocytrate dehydrogenase and $1.5 \mathrm{mg}$ of proteins. After $10 \mathrm{~min}$ of incubation at $37^{\circ} \mathrm{C}$, the reaction was terminated by addition of $0.5 \mathrm{ml}$ of $0.6 \mathrm{~N}$ perchloric acid. Precipitated proteins were removed by centrifugation and $1 \mathrm{ml}$ of the resultant supernatant was mixed with $1 \mathrm{ml}$ of $10 \mathrm{~N} \mathrm{NaOH}$. Absorbance at $546 \mathrm{~nm}$ was immediately recorded and 4-nitrocathecol determined $\left(\varepsilon=10.28 \mathrm{mM}^{-1} \mathrm{~cm}^{-1}\right)$ [41].

2.6.5. Pentoxyresorufin O-dealkylase (PROD), ethoxyresorufin O-deethylase, (EROD) and methoxyresorufin O-demethylase (MROD)

Reaction mixture (PROD) consisted of $0.025 \mathrm{mM} \mathrm{MgCl}_{2}, 200 \mathrm{mM}$ pentoxyresorufin, $0.32 \mathrm{mg}$ of proteins and $130 \mathrm{mM}$ NADPH in $2.0 \mathrm{ml}$ $0.05 \mathrm{M}$ Tris- $\mathrm{HCl}$ buffer ( $\mathrm{pH}$ 7.4). Resorufin formation at $37^{\circ} \mathrm{C}$ was calculated by comparing the rate of increase in relative fluorescence to the fluorescence of known amounts of resorufin (excitation $563 \mathrm{~nm}$, emission $586 \mathrm{~nm}$ ) [42]. EROD and MROD activities were measured exactly in the same manner as described for the pentoxyresorufin assay, except that substrate concentration was $1.7 \mathrm{mM}$ for ethoxyresorufin and $5 \mathrm{mM}$ for methoxyresorufin [43].

\subsubsection{Ethoxycoumarin O-deethylase (ECOD)}

ECOD was determined by quantification of umbelliferone formation, according to Aitio A. [44]. Incubation mixture was consisted of $2.6 \mathrm{ml}$, composed of $1 \mathrm{mM}$ ethoxycoumarin, $5 \mathrm{mM} \mathrm{MgCl}_{2}$, NADPH-generating system (see aminopyrine assay) and $0.25 \mathrm{ml}$ of sample. After $5 \mathrm{~min}$ of incubation at $37{ }^{\circ} \mathrm{C}$ reaction was stopped by addiction of $0.85 \mathrm{ml}$ of trichloroacetic acid (TCA) $0.31 \mathrm{M}$. The $\mathrm{pH}$ of the mixture was brought to

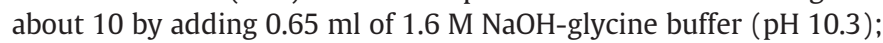
amount of umbelliferone was measured fluorimetrically (excitation $390 \mathrm{~nm}$; emission $440 \mathrm{~nm}$ ).

\subsection{Phase II enzymes}

\subsubsection{Glutathione S-transferase (GST)}

The incubation mixture for measuring overall GST activity contained $1 \mathrm{mM}$ glutathione $+1 \mathrm{mM}$ 1-chloro-2,4-dinitrobenzene (CDNB) in methanol $+0.025 \mathrm{ml}$ of sample in a final volume of $2.5 \mathrm{ml} 0.1 \mathrm{M}$ phosphate $\mathrm{Na}+/ \mathrm{K}+$ buffer ( $\mathrm{pH} 6.5$ ). The product of the reaction of the thiol group of glutathione with the electrophilic group of CDNB was read at $340 \mathrm{~nm}\left(\varepsilon=9.6 \mathrm{mM}^{-1} \mathrm{~cm}^{-1}\right)[45,46]$.

\subsubsection{UDP-glucuronosyl transferase (UDP-GT)}

UDP-GT was determined kinetically using 1-naphtol as substrate (final concentration, $50 \mathrm{mM}$ ) by the continuous fluorimetric (excitation $390 \mathrm{~nm}$; emission $440 \mathrm{~nm}$ ) monitoring of 1-naphtholglucuronide production in the presence of $1 \mathrm{mM}$ uridine-5'-diphosphoglucuronic acid [47]. Experiments were performed in the presence or absence of Triton $\mathrm{X}-100(0.2 \%)$ as a detergent, in order to improve the assay sensitivity [48].

\subsection{Antioxidant enzymes}

\subsubsection{Catalase (CAT)}

The reaction was started in a quartz cuvette, containing $50 \mathrm{mM}$ potassium phosphate buffer and cytosol sample, by adding $30 \mathrm{mM}$ $\mathrm{H}_{2} \mathrm{O}_{2}$. The decomposition of the substrate was measured at $240 \mathrm{~nm}$ and catalase activity was expressed as moles of $\mathrm{H}_{2} \mathrm{O}_{2}$ consumed per minute per mg protein using a molar extinction coefficient of $43.6 \mathrm{mM}^{-1} \mathrm{~cm}^{-1}[49]$.

\subsection{2. $N A D(P) H: q u i n o n e ~ r e d u c t a s e(N Q O 1)$}

NQO1 activity was assayed spectrophotometrically at $600 \mathrm{~nm}$ by monitoring the reduction of the blue redox dye of 2-6

Table 2

Expression of cyp-linked monooxygenase in renal subcellular fractions from VE treated rats.

\begin{tabular}{|c|c|c|c|c|c|}
\hline \multirow[t]{2}{*}{ Parameters } & \multirow[t]{2}{*}{ Controls } & \multicolumn{2}{|c|}{ Treatment (seven days) } & \multicolumn{2}{|c|}{ Treatment (fourteen days) } \\
\hline & & $100 \mathrm{mg} / \mathrm{kg}$ b.w. & $200 \mathrm{mg} / \mathrm{kg}$ b.w. & $100 \mathrm{mg} / \mathrm{kg}$ b.w. & $200 \mathrm{mg} / \mathrm{kg}$ b.w. \\
\hline p-Nitrophenol hydroxylase $\left(\mathrm{nmol} \times \mathrm{mg}^{-1} \times \min ^{-1}\right)(\mathrm{CYP} 2 \mathrm{E} 1)$ & $0.36 \pm 0.08$ & $0.38 \pm 0.04^{*}$ & $0.70 \pm 0.04^{* *}$ & $0.72 \pm 0.08^{* *}$ & $0.93 \pm 0.07^{* *}$ \\
\hline Ethoxycoumarin $O$-deethylase $\left(\mathrm{pmol} \times \mathrm{mg}^{-1} \times \min ^{-1}\right)$ & $0.66 \pm 0.01$ & $0.51 \pm 0.01^{* *}$ & $0.53 \pm 0.02^{* *}$ & $0.55 \pm 0.01^{* *}$ & $0.51 \pm 0.01^{* *}$ \\
\hline Pentoxyresorufin $O$-dealkylase $\left(\mathrm{pmol} \times \mathrm{mg}^{-1} \times \mathrm{min}^{-1}\right)(\mathrm{CYP} 2 \mathrm{~B} 1 / 2)$ & $0.34 \pm 0.08$ & $0.47 \pm 0.03^{* *}$ & $0.32 \pm 0.02^{*}$ & $0.45 \pm 0.05^{* *}$ & $0.68 \pm 0.08^{* *}$ \\
\hline Ethoxyresorufin $O$-deethylase $\left(\mathrm{pmol} \times \mathrm{mg}^{-1} \times \mathrm{min}^{-1}\right)(\mathrm{CYP} 1 \mathrm{~A} 1)$ & $3.61 \pm 0.28$ & $3.78 \pm 0.12^{* *}$ & $5.87 \pm 0.43^{* *}$ & $3.93 \pm 0.28$ & $4.60 \pm 0.15^{* *}$ \\
\hline Methoxyresorufin $O$-demethylase $\left(\mathrm{pmol} \times \mathrm{mg}^{-1} \times \min ^{-1}\right)(\mathrm{CYP} 1 \mathrm{~A} 2)$ & $1.59 \pm 0.14$ & $2.67 \pm 0.24^{* *}$ & $3.37 \pm 0.33^{* *}$ & $1.75 \pm 0.15$ & $2.50 \pm 0.18^{* *}$ \\
\hline
\end{tabular}

Each value represents the mean \pm S.D. of six independent experiments on six rats. See Section 2 for details and experimental procedures.

Mean values were significantly different compared with the control groups (Wilcoxon's rank method): ${ }^{*} \mathrm{p}<0.05,{ }^{* *} \mathrm{p}<0.01$. 
Table 3

Phase-II enzymes in hepatic subcellular fractions from VE treated rats.

\begin{tabular}{|c|c|c|c|c|c|}
\hline \multirow[t]{2}{*}{ Parameters } & \multirow[t]{2}{*}{ Controls } & \multicolumn{2}{|c|}{ Treatment (seven days) } & \multicolumn{2}{|c|}{ Treatment (fourteen days) } \\
\hline & & 100 mg/kg b.w. & $200 \mathrm{mg} / \mathrm{kg}$ b.w. & 100 mg/kg b.w. & $200 \mathrm{mg} / \mathrm{kg}$ b.w. \\
\hline Glutathione S-transferase $(\mathrm{GST})\left(\mathrm{nmol} \times \mathrm{mg}^{-1} \times \mathrm{min}^{-1}\right)$ & $11.01 \pm 0.18$ & $10.73 \pm 0.73$ & $9.71 \pm 0.18^{* *}$ & $12.53 \pm 0.27^{* *}$ & $11.76 \pm 0.19^{*}$ \\
\hline UDPglucuronosyl-transferase (UDPGT) $\left(\mathrm{nmol} \times \mathrm{mg}^{-1} \times \min ^{-1}\right)$ & $4.46 \pm 0.32$ & $4.03 \pm 0.24$ & $4.94 \pm 0.13^{*}$ & $4.92 \pm 0.57$ & $3.90 \pm 0.50$ \\
\hline
\end{tabular}

Each value represents the mean \pm S.D. of six independent experiments on six rats. See Section 2 for details and experimental procedures.

Mean values were significantly different compared with the control groups (Wilcoxon's rank method): ${ }^{*} \mathrm{p}<0.05,{ }^{* *} \mathrm{p}<0.01$.

dichlorophenolindophenol (DCPIP) $\left(\varepsilon=9.6 \mathrm{mM}^{-1} \mathrm{~cm}^{-1}\right)$, and expressed as moles of DCPIP reduced per minute per mg protein [50].

\subsection{Electronic paramagnetic resonance (EPR) spectroscopy}

Briefly, a small weighted portion of renal tissue from VE treated groups (mean weight $=2.7 \pm 1.3 \mathrm{mg}$ ) and controls (mean weight $=$ $2.4 \pm 1.2 \mathrm{mg}$ ) was cut from each animal and immediately treated with $1 \mathrm{ml}$ of $1 \mathrm{mM}$ hydroxylamine probe. The hydroxylamine employed in this work was bis(1-hydroxy-2,2,6,6-tetramethyl-4-piperidinyl) decandioate, capable of efficiently trapping the majority of oxygen-, carbon- and nitrogen-centred radicals, including superoxide and peroxynitrite [51]. This reaction yields a very persistent nitroxide that can be readily detected and accurately quantified by EPR spectroscopy [51-54]. Samples were prepared by treating the tissue with $1 \mathrm{ml}$ of standard physiological solution containing the hydroxylamine probe $(1 \mathrm{mM})$ and EDTA ( $1 \mathrm{mM})$ as metal chelating agent. After 5 min incubation at $37^{\circ} \mathrm{C}$, the sample was snap frozen in liquid nitrogen to stop any reaction and stored at $-80{ }^{\circ} \mathrm{C}$ until EPR measurement was performed. The optimal incubation time and the most appropriate experimental conditions were determined in previous investigations [51-53]. Immediately before measurement, the sample was warmed to room temperature, and about $50 \mu \mathrm{l}$ of the solution was transferred and sealed in a calibrated capillary glass tube, which was placed inside the cavity of a Bruker ESP 300 EPR spectrometer (Bruker Biospin S.r.l., Rheinstetten, Germany) equipped with an nuclear magnetic resonance gaussmeter for field calibration, a Bruker ER 033 M FF-lock (Bruker Biospin S.r.l.) and a Hewlett-Packard 5350B microwave frequency counter (Hewlett Packard, Houston, TX, USA). The actual amount of solution analyzed was chosen so as to cover the entire sensitive area of the instrument cavity. The spectra of the nitroxide radical, generated by the reaction of the probe with the radicals produced in the tissue, were then recorded using the following instrumental settings: modulation amplitude $=$ $1 \cdot 0 \mathrm{G}$; conversion time $=163 \cdot 84 \mathrm{~ms}$; time constant $=163 \cdot 84 \mathrm{~ms}$; modulation frequency $100 \mathrm{kHz}$; microwave power $=6.4 \mathrm{~mW}$. The intensity of the first spectral line of the nitroxide ( $a \mathrm{~N}=16.60 \mathrm{G}$; $\mathrm{g}=2 \cdot 0056$ ) was used to obtain the absolute amount of nitroxide per $\mathrm{ml}$ of sample, after calibration of the spectrometer response with known solutions of TEMPO-coline in water, using an ER 4119HS Bruker Marker Accessory as internal standard. For simplicity, results were expressed as $\mu \mathrm{mol}$ of ROS in $\mathrm{g}$ of tissue. The hydroxylamine probe (CAS no. 314726-62-0) was prepared as previously described [52,53].

\subsection{Statistical analysis}

Statistical evaluation was performed using the Wilcoxon's rank test to assess significant differences in the considered parameters between the groups of treated animals compared with controls [55].

\section{Results}

\subsection{Body and organ weights, blood parameters}

There were no differences in body or organ weights between VE treated groups and their relative controls (data not shown). VE did not significantly affect haematological or biochemical parameters (data not shown).

\subsection{Effects of VE treatment on hepatic phase-I enzymes, single probes}

Table 1 shows hepatic CYP content, CYP-reductase activity and various mixed function monooxygenases measured both in controls and VE treated animals using the following selected substrates as probes of different CYP isoenzymes: aminopyrine (preferential to CYP3A4), p-nitrophenol (CYP2E1), ethoxycoumarin (mixed), penthoxyresorufin (CYP2B1/2), methoxyresorufin (CYP1A2), ethoxyresorufin (CYP1A1).

A general down regulation for many of the tested CYP isoforms, especially after fourteen-day treatment, was recorded. Ethoxyresorufin $O$-deethylase (EROD) was strongly inactivated to different extents in all situations (ranging from $21 \%$ to $32 \%$ loss; $\mathrm{p}<0.01$ ). NADPH-cytochrome (P450) c-reductase was down regulated up to $19 \%$ after fourteen-day administration at the lowest dose tested $(p<0.01)$. The longest supplementation exerted a weak but significant $(\mathrm{p}<0.01)$ reduction $\mathrm{N}$ -

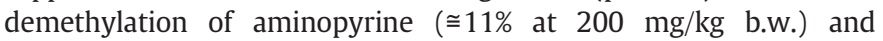
methoxyresorufin 0 -demethylase (MROD) (almost $18 \%$ at $100 \mathrm{mg} / \mathrm{kg}$ b.w. and $31 \%$ at $200 \mathrm{mg} / \mathrm{kg}$ b.w., p < 0.01). On the contrary, at $200 \mathrm{mg} / \mathrm{kg}$ b.w. dose, CYP content and pentoxyresorufin O-dealkylase (CYP2B1/2) were slightly increased up to, respectively, $13 \%$ and $37 \%$ after seven-day treatment ( $\mathrm{p}<0.01$ ). The CYP2E1 associated activity showed a modest increment both after seven- and fourteen-day treatments at the highest dose, while the lowest dose caused a weak inactivation after fourteen-day treatment (about 5\% loss; $\mathrm{p}<0.01$ ).

\subsection{Effects of VE treatment on renal phase-I enzymes, single probes}

Table 2 reports the expression of CYP-linked monooxygenases in renal subcellular preparations. At both dosages employed and

Table 4

Phase-II enzymes in renal subcellular fraction from VE treated rats.

\begin{tabular}{|c|c|c|c|c|c|}
\hline \multirow[t]{2}{*}{ Parameters } & \multirow[t]{2}{*}{ Controls } & \multicolumn{2}{|c|}{ Treatment (seven days) } & \multicolumn{2}{|c|}{ Treatment (fourteen days) } \\
\hline & & 100 mg/kg b.w. & $200 \mathrm{mg} / \mathrm{kg}$ b.w. & $100 \mathrm{mg} / \mathrm{kg}$ b.w. & $200 \mathrm{mg} / \mathrm{kg}$ b.w. \\
\hline Glutathione S-transferase $(\mathrm{GST})\left(\mathrm{nmol} \times \mathrm{mg}^{-1} \times \mathrm{min}^{-1}\right)$ & $0.32 \pm 0.01$ & $0.23 \pm 0.01^{* *}$ & $0.27 \pm 0.01^{*}$ & $0.26 \pm 0.01^{* *}$ & $0.25 \pm 0.01^{* *}$ \\
\hline UDPglucuronosyl-transferase (UDPGT) $\left(\mathrm{nmol} \times \mathrm{mg}^{-1} \times \min ^{-1}\right)$ & $1.19 \pm 0.06$ & $0.51 \pm 0.06^{* *}$ & $0.54 \pm 0.07^{* *}$ & $0.63 \pm 0.11^{* *}$ & $0.63 \pm 0.02^{* *}$ \\
\hline
\end{tabular}

Each value represents the mean \pm S.D. of six independent experiments on six rats. See Section 2 for details and experimental procedures.

Mean values were significantly different compared with the control groups (Wilcoxon's rank method): ${ }^{*} \mathrm{p}<0.05,{ }^{* *} \mathrm{p}<0.01$. 
Table 5

Antioxidant enzymes in hepatic cytosol from VE treated male rats.

\begin{tabular}{|c|c|c|c|c|c|}
\hline \multirow[t]{2}{*}{ Parameters } & \multirow[t]{2}{*}{ Controls } & \multicolumn{2}{|c|}{ Treatment (seven days) } & \multicolumn{2}{|c|}{ Treatment (fourteen days) } \\
\hline & & 100 mg/kg b.w. & 200 mg/kg b.w. & 100 mg/kg b.w. & $200 \mathrm{mg} / \mathrm{kg}$ b.w. \\
\hline Catalase $\left(\mu \mathrm{mol} \times \mathrm{mg}^{-1} \times \mathrm{min}^{-1}\right)$ & $3.47 \pm 0.33$ & $6.00 \pm 0.56^{* *}$ & $4.18 \pm 0.44^{*}$ & $5.41 \pm 0.65^{* *}$ & $2.49 \pm 0.21^{* *}$ \\
\hline $\mathrm{NAD}(\mathrm{P}) \mathrm{H}$ :quinone reductase $\left(\mu \mathrm{mol} \times \mathrm{mg}^{-1} \times \min ^{-1}\right)$ & $8.73 \pm 0.50$ & $8.37 \pm 0.90$ & $13.31 \pm 1.50^{* *}$ & $9.51 \pm 1.13^{* *}$ & $10.72 \pm 1.19^{* *}$ \\
\hline
\end{tabular}

Each value represents the mean \pm S.D. of six independent experiments on six rats. See Section 2 for details and experimental procedures.

Mean values were significantly different compared with the control groups (Wilcoxon's rank method): ${ }^{*} \mathrm{p}<0.05,{ }^{* *} \mathrm{p}<0.01$.

observational times, a prevalent up regulation was noted for the majority of the tested CYP isoforms. CYP2E1 associated activity presented a significant increase at all doses tested; in particular, a 2-fold increase was seen after seven days at $200 \mathrm{mg} / \mathrm{kg}$ b.w. and after fourteen-day treatment at $100 \mathrm{mg} / \mathrm{kg}$ b.w. $(\mathrm{p}<0.01)$. These increments became greater (up to 2.6-fold) after fourteen days at the highest dose tested $(\mathrm{p}<0.01)$. VE significantly increased $(\mathrm{p}<0.01)$ PROD up to $32 \%$ after seven or fourteen lowest doses; the phenomenon reached 2-fold induction $(\mathrm{p}<0.01)$ after highest dose administration (both treatment periods). EROD activity was up regulated after seven- or fourteenday highest dose treatment (almost up to 63\% and 27\% respectively, $\mathrm{p}<0.01)$. CYP1A2-linked activity was more than doubled $(\mathrm{p}<0.01)$ by seven-day treatment at $200 \mathrm{mg} / \mathrm{kg}$ b.w.; the same timing at the lowest dose, as well as fourteen-day treatment at the highest dose, were able to increase MROD ( $p<0.01$ ), even if the alteration was more modest (up to $68 \%$ and $57 \%$, respectively). In contrast, VE significantly decreased $(\mathrm{p}<0.01)$ ECOD (almost 30\% loss after seven days at $100 \mathrm{mg} / \mathrm{kg}$ b.w., $20 \%$ and $17 \%$ loss, after seven-day highest dose, or fourteen-day lowest dose treatments, respectively).

\subsection{Effects of VE on hepatic phase-II enzymes (GST and UDPGT)}

Table 3 shows how VE was not able to provoke relevant changes in hepatic phase-II enzymes. GST reported mild fluctuations, as a $12 \%$ loss occurred after seven-day highest dose administration $(\mathrm{p}<0.01)$. Contextually, fourteen-day treatment, at both dosages, caused upregulation up to almost $14 \%$ at $100 \mathrm{mg} / \mathrm{kg}$ b.w., $\mathrm{p}<0.01$, and up to $7 \%$ at $200 \mathrm{mg} / \mathrm{kg}$ b.w. $\mathrm{p}<0.05$. UDPGT was not affected by VE treatment, with the exception of $200 \mathrm{mg} / \mathrm{kg}$ b.w. that showed a nearly $11 \%$ increase $(\mathrm{p}<0.05)$ after seven-day treatment.

\subsection{Effects of VE on kidney on renal phase-II enzymes (GST and UDPGT)}

Contrary to what was observed in the liver, Table 4 reports a relevant inactivating effect attributable to VE.

GST activity, in terms of CDNB metabolism, was inactivated in all cases, ranging from $16 \%$ loss ( $p<0.05$ ) to $28 \%$ loss $(\mathrm{p}<0.01$ ) after seven-day treatment for either dose. This phenomenon was further exacerbated for UDPGT activity, which recorded important decreases (ranging from $47 \%$ to $57 \%$ loss; $\mathrm{p}<0.01$ ) in each group.

\subsection{Effects of VE on hepatic antioxidant enzymes}

Seven- or fourteen-day lowest dose treatments exerted a modest increment of CAT (up to $73 \%$ and 56\%, respectively), while highest dose treatments caused a 20\% ( $p<0.05)$ increase after seven-day administration, and a 28\% ( $\mathrm{p}<0.01)$ decrease after fourteen-day treatment (Table 5).

NAD(P)H-quinone reductase was significantly induced $(59 \%, \mathrm{p}<$ 0.01 ), in seven- or fourteen-day $200 \mathrm{mg} / \mathrm{kg}$ b.w. groups.

\subsection{Effects of VE on renal antioxidant enzymes}

VE decreased $\mathrm{NAD}(\mathrm{P}) \mathrm{H}$ : quinone reductase in all cases (ranging from $20 \%$ to $44 \%$ loss). Catalase recorded a $20 \%$ ( $p<0.01$ ) increase at the lowest dose after seven-day supplementation, while the highest dose administered for the longest treatment period induced an $11 \%$ loss $(\mathrm{p}<0.01)$ (Table 6$)$.

\subsection{EPR radical probe measurements in renal tissue}

EPR spectroscopy coupled to a radical probe technique was used to assess the level of reactive (oxidizing) radical species, in renal tissue. As shown in Table 7 and Fig. 1, we found a significant over-generation of free radicals in the samples collected from VE treated animal groups. The rate of production of the stable nitroxide radical representing the rate of reactive oxygen species in the tissue was more than 2-fold greater in each experimental treated unit compared to controls $(\mathrm{p}<0.05)$.

\section{Discussion}

Our survey has outlined a complex picture in which VE exerts its effects in a completely organ-specific way. The almost neutral behaviour shown by VE on hepatic phase I and II enzyme activities, and at the same time the appreciable increase of the antioxidant machinery considered in this study (Catalase and $\mathrm{NAD}(\mathrm{P}) \mathrm{H}$ :quinone reductase) would once again stick the label of "protective agent" on VE. On the contrary, if we take into account data from the kidneys, the picture appears very different from what was recorded in the liver.

In the animal model that we proposed here, VE administration produced a booster effect on renal phase I carcinogen bioactivating enzymes.

If extrapolated to humans, the recorded CYPs inductions might have serious toxicological relevance.

In both experimental animals and humans it is well established that xenobiotic metabolizing enzymes can be induced by a wide range of drugs, pesticides, food additives, industrial chemicals, natural products and environmental pollutants [56].

On one hand, CYP changes may alter both endogenous metabolism (e.g., Leukotrienes, Vitamin D, arachidonic acid derivatives, nitric oxide, aldosterone and cholesterol metabolism) and crucial physiological functions such as growth, differentiation, apoptosis and neuroendocrine

Table 6

Antioxidant enzymes in renal cytosol from VE treated rats.

\begin{tabular}{|c|c|c|c|c|c|}
\hline \multirow[t]{2}{*}{ Parameters } & \multirow[t]{2}{*}{ Controls } & \multicolumn{2}{|c|}{ Treatment (seven days) } & \multicolumn{2}{|c|}{ Treatment (fourteen days) } \\
\hline & & 100 mg/kg b.w. & 200 mg/kg b.w. & $100 \mathrm{mg} / \mathrm{kg}$ b.w. & $200 \mathrm{mg} / \mathrm{kg}$ b.w. \\
\hline Catalase $\left(\mu \mathrm{mol} \times \mathrm{mg}^{-1} \times \min ^{-1}\right)$ & $6.36 \pm 0.18$ & $7.60 \pm 0.87^{* *}$ & $6.96 \pm 0.37^{*}$ & $6.37 \pm 0.19$ & $5.64 \pm 0.17^{* * *}$ \\
\hline $\mathrm{NAD}(\mathrm{P}) \mathrm{H}$ :quinone reductase $\left(\mu \mathrm{mol} \times \mathrm{mg}^{-1} \times \min ^{-1}\right)$ & $3.40 \pm 0.14$ & $2.52 \pm 0.30^{* *}$ & $2.54 \pm 0.24^{* *}$ & $2.72 \pm 0.18^{*}$ & $1.92 \pm 0.11^{* *}$ \\
\hline
\end{tabular}

Each value represents the mean \pm S.D. of six independent experiments on six rats. See Section 2 for details and experimental procedures.

Mean values were significantly different compared with the control groups (Wilcoxon's rank method): ${ }^{*} \mathrm{p}<0.05,{ }^{* *} \mathrm{p}<0.01$. 
functions. On the other hand, the increased bioactivation of ubiquitous pro-mutagens/pro-carcinogens, saturating the enzymes involved in "error-free repair", can seriously place DNA at structural damage risk.

Furthermore, the existence of NADPH-dependent production of reactive oxygen species (ROS) $\left(\mathrm{O}_{2}^{-}, \mathrm{H}_{2} \mathrm{O}_{2}\right.$, and $\left.\mathrm{HO} \cdot\right)$ by microsomes has been known for several decades and has been linked to CYP induction [57]; more recently, it was discovered that the regulation of various CYP isoforms including CYP1A, CYP2B, CYP3A, CYP4A, and virtually any CYP can generate very large amounts of ROS [58]. In other terms, the induction of any of these CYPs leads to increased ROS production, and this phenomenon has also been observed in studies reporting NADPH-stimulated release of ROS by subcellular preparations enriched in specific human CYPs [30]. The phenomenon could intensify further in genetically predisposed individuals who inherit certain 'high-risk' polymorphisms affecting carcinogen-metabolizing enzymes [59,60], as well as individuals who lack adequate detoxication or DNA repair capacity [61-63].

For example, the 2.6-fold increment of CYP2E1-linked activity that we recorded could rise in a putative alcohol consumer. Alcohol, which is itself an inducer of CYP2E1, can thus act with VE in boosting phase-I reactions; irrespective of the fact that genetic polymorphisms lead to the occurrence of high or poor-metabolizer phenotypes in the population [64], that further complicate the issue.

Moreover, it has been shown how CYP2E1 is one of the most active CYP isoforms in generating ROS associated with cancer progression and metastasis [65]; and recent evidence by León-Buitimea et al. supports the hypothesis that ethanol enhances oxidative stress in MCF10 A cells overexpressing CYP2E1, increasing human mammary cell activation, via an EGFR-dependent signalling mechanism associated with oxidative stress [66]. Translated to humans, the doubling in CYP1A1 and CYP1A2 linked activity, which activates polycyclic aromatic hydrocarbons (PAHs), would be of particular concern for smokers who are exposed to a wide range of procarcinogens that are bioactivated by the CYP apparatus, irrespective of the fact that many PAHs are themselves recognized CYP inducers [67].

Discussing the link between the CYP induction and its role on cancer, it should be also kept in mind that most of CYP forms induction takes place through the involvement of nuclear receptors such as the aryl hydrocarbon receptor (AhR), the constitutive androstane receptor (CAR), the pregnane $\mathrm{X}$ receptor (PXR) and the peroxisome proliferatoractivated receptor alpha (PPAR $\alpha$ ). The pleiotropic response triggered by the activation of nuclear receptors can affect not only genes involved in the xenobiotic metabolism, but also those associated to physiological processes including cell proliferation [68]. For this reason, CYP induction cannot be considered only a metabolism concern, but it can be also a marker of transcription factor activation and a potential tumorigenesis sentinel. Recently, the chronic exposure of rodents to non-genotoxic CYP inducers was associated to the formation of tumours in several tissues [56].

Furthermore, the remarkable decrement observed in kidney of post oxidative enzyme activities (GST and UDPGT), and the subtler, but still important one of the enzyme-dependant antioxidant machinery highlights a lack in detoxifying capacity and an increased vulnerability to further ROS insults. Under these conditions, it appears that the fine balance between the generation of oxygen centred species and the cellular

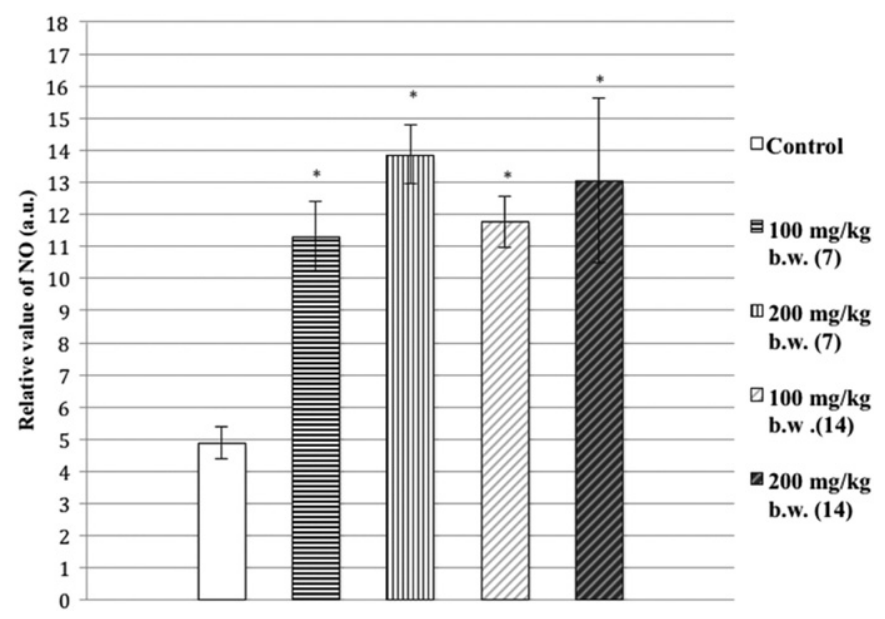

Fig. 1. Oxygen free radical species in kidney. Bars represent the amount of ROS. Measures were performed by the use of EPR spectrometry and they are expressed as the intensity of nitroxide EPR signal. Mean values were significantly different compared with the control groups (Wilcoxon's rank method): ${ }^{*} \mathrm{p}<0.05,{ }^{* *} \mathrm{p}<0.01$.

defences may be tilted in favour of oxidative stress, leading to putative macromolecular damage that can finally point toward cancer.

Due to the widely recognized role of ROS as a factor that may increase the incidence of cancer in humans, we used EPR spectroscopy coupled to a radical probe technique, in order to evaluate the hypothesized contribution of CYPs observed induction on free radical generation in renal tissue.

Our data showed a significant increase of ROS in renal tissue samples collected from VE treated rats compared with controls: more than doubled values were recorded throughout each treatment. These findings lead to consider the hypothesis that VE could potentially increase cancer risk rather than preventing it, by inducing carcinogen-activating enzymes and enhancing oxidative stress status, that can play a role in the promotion and in virtually all steps of the carcinogenesis process [69,70].

Bearing in mind the limitation of a rat model, it is conceivable that the results of the present study support the observed cancerpromoting effect reported by $\mathrm{Wu}$ and co-workers [24], exemplified in a co-carcinogenic potential through different mechanisms; and, more in general, our findings may help explain previous contradictory evidence regarding VE supplementation and cancer incidence.

These findings and the emerging conclusions should not be a surprise, if we look at "unexpected" results of cancer chemoprevention trials testing the effects of $\beta$-carotene on the risk of chronic diseases such as cancer. $\beta$-carotene administered alone or in combination with vitamins for prevention of lung and other cancers in heavy smokers or asbestos workers failed to reduce cancer risk, and, in some cases, actually increased it [71-73]. Even in that case, it was documented that the harmful effects of $\beta$-carotene could be linked to its ability to stimulate metabolizing machinery, increasing bioactivation and enhancing ROS levels [74].

The term "antioxidant paradox" has been used for several years to refer to the observations that giving large doses of antioxidants to

Table 7

ROS levels in kidney tissue from VE treated rats.

\begin{tabular}{|c|c|c|c|c|c|}
\hline \multirow[t]{2}{*}{ Tissue } & \multirow[t]{2}{*}{ Controls } & \multicolumn{2}{|c|}{ Treatment (seven days) } & \multicolumn{2}{|c|}{ Treatment (fourteen days) } \\
\hline & & $100 \mathrm{mg} / \mathrm{kg}$ b.w. & $200 \mathrm{mg} / \mathrm{kg}$ b.w. & $100 \mathrm{mg} / \mathrm{kg}$ b.w. & $200 \mathrm{mg} / \mathrm{kg}$ b.w. \\
\hline Kidney (a.u.) & $4.88 \pm 0.24$ & $11.30 \pm 1.06^{*}$ & $13.84 \pm 0.91^{*}$ & $11.75 \pm 0.79^{*}$ & $13.03 \pm 2.56^{*}$ \\
\hline
\end{tabular}

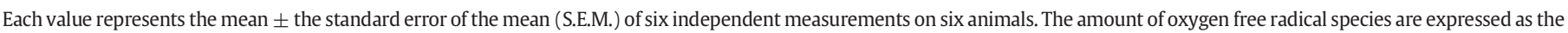
intensity of nitroxide EPR signal.

Mean values were significantly different compared with the control groups (Wilcoxon's rank method): ${ }^{*} \mathrm{p}<0.05,{ }^{* *} \mathrm{p}<0.01$. 
humans, in most studies, had no preventive or therapeutic effects [75, 76]; despite this, the market of vitamins is rising, worldwide, and many tons of vitamin $\mathrm{E}$ have been consumed by the population with no beneficial effects to their health and even a suggestion of harm [77].

The even more relevant fact is that, out of all the people who usually consume multivitamin cocktails, most of them take supplements not to treat a diagnosed deficiency, but to improve their health condition $[77,78]$. Our data bring to light a dark side of VE that is astonishingly similar to that of $\beta$-carotene and point out, once again, how harmful the well-embedded concept that "antioxidants are good, more antioxidants are better" could be [79].

We agree with Wenner Moyer M. in replying to the question "are supplements useful?" that the state of the art offers only an equivocal half-answer: "maybe yes" for some individuals, nutrients and doses, and "maybe no" for others [78].

\section{Conclusions}

Our study provides a further example of the potentially harmful effects of recommending supplementations with micronutrients on a large scale.

Furthermore, we hypothesize that the increased cancer risk observed in long-term clinical trials and the "paradoxical" ability of VE to generate oxidative stress which we have shown herein may be related. In the light of recent evidence, assuming that daily VE supplementation could, at worst, be ineffective should be carefully reconsidered. On the other hand, if cancer chemotherapy as often as possible involves multiple agents in order to prevent clonal selection, why would cancer chemoprevention be based on a single agent [80]?

\section{Author contribution to study}

FV, DC, AS and MP designed the study. DC, FV, AS, AV, CMDC, VL conducted the study in vivo and data analysis. PF and ML performed EPR measurements and relative data analysis. FV, DC and MP wrote the manuscript. All authors discussed, edited and approved the final version.

\section{Conflict of interest statement}

The authors declare that there are no conflicts of interest.

\section{Acknowledgements}

All sources of financial and material support were provided by a grant from the Italian Ministry of Education, University and Research (grant no. RFOCANIS09).

\section{References}

[1] G.W. Burton, M.G. Traber, R.V. Acuff, D.N. Walters, H. Kayden, L. Hughens, K.U. Ingold, Human plasma and tissue alpha-tocopherol concentrations in response to supplementation with deuterated natural and synthetic vitamin E, Am J Clin Nutr. 67 (1998) 669-684.

[2] A. Rigotti, Absorption, transport, and tissue delivery of vitamin E, Mol Aspects Med. 28 (2007) 423-436.

[3] J.H. Wu, K.D. Croft, Vitamin E metabolism, Mol Aspects Med. 28 (2007) 437-452.

[4] J.N. Hathcock, A. Azzi, J. Blumberg, T. Bray, A. Dickinson, B. Frei, I. Jialal, C.S. Johnston, F.J. Kelly, K. Kraemer, L. Packer, S. Parthasarathy, H. Sies, M.G. Traber, Vitamins E and C are safe across a broad range of intakes, Am. J. Clin. Nutr. 81 (2005) 736-745.

[5] M.J. Stampfer, W.C. Willett, Homocysteine and marginal vitamin deficiency. The importance of adequate vitamin intake, J. Am. Med. Assoc. 270 (1993) 2726-2727.

[6] H.Y. Huang, L.J. Appel, Supplementation of diets with alpha-tocopherol reduces serum concentrations of gamma- and delta-tocopherol in humans, J. Nutr. 133 (2003) 3137-3140.

[7] S. Blum, M. Vardi, J.B. Brown, A. Russell, U. Milman, C. Shapira, N.S. Levy, R. MillerLotan, R. Asleh, A.P. Levy, Vitamin E reduces cardiovascular disease in individuals with diabetes mellitus and the haptoglobin 2-2 genotype, Pharmacogenomics 11 (2010) 675-684.
[8] J. Ju, S.C. Picinich, Z. Yang, Y. Zhao, N. Suh, A.N. Kong, C.S. Yang, Cancer-preventive activities of tocopherols and tocotrienols, Carcinogenesis 31 (2010) 533-542.

[9] E. Niki, Do free radicals play causal role in atherosclerosis? Low density lipoprotein oxidation and vitamin E revisited, J. Clin. Biochem. Nutr. 48 (2011) 3-7.

[10] The alpha-tocopherol, beta-carotene lung cancer prevention study: design, methods, participant characteristics, and compliance. The ATBC Cancer Prevention Study Group. Ann. Epidemiol. 4 (1994) 1-10.

[11] L.C. Clark, G.F. Combs Jr., B.W. Turnbull, E.H. Slate, D.K. Chalker, J. Chow, L.S. Davis, R.A. Glover, G.F. Graham, E.G. Gross, A. Krongrad, J.L. Lesher Jr., H.K. Park, B.B. Sanders Jr., C.L. Smith, J.R. Taylor, Effects of selenium supplementation for cancer prevention in patients with carcinoma of the skin. A randomized controlled trial. Nutritional Prevention of Cancer Study Group, JAMA 276 (1996) 1957-1963.

[12] W.J. Blot, J.Y. Li, P.R. Taylor, W. Guo, S. Dawsey, G.Q. Wang, C.S. Yang, S.F. Zheng, M. Gail, G.Y. Li, Y. Yu, B.-q. Liu, J. Tangrea, Y. Sun, F. Liu, J.F. Fraumeni, Y.H. Zhang, B. Li, Nutrition intervention trials in Linxian, China: supplementation with specific vita$\mathrm{min} /$ mineral combinations, cancer incidence, and disease-specific mortality in the general population, J. Natl. Cancer Inst. 85 (1993) 1483-1492.

[13] P.R. Taylor, D. Albanes, Selenium, vitamin E, and prostate cancer-ready for prime time? J. Natl. Cancer Inst. 90 (1998) 1184-1185.

[14] N. Fleshner, W.R. Fair, R. Huryk, W.D. Heston, Vitamin E inhibits the high-fat diet promoted growth of established human prostate LNCaP tumors in nude mice, J. Urol. 161 (1999) 1651-1654.

[15] D.P. Vivekananthan, M.S. Penn, S.K. Sapp, A. Hsu, E.J. Topol, Use of antioxidant vitamins for the prevention of cardiovascular disease: meta-analysis of randomised trials, Lancet 361 (2003) 2017-2023.

[16] P.G. Shekelle, S.C. Morton, L.K. Jungvig, J. Udani, M. Spar, W. Tu, M.J. Suttorp, I. Coulter, S.J. Newberry, M. Hardy, Effect of supplemental vitamin E for the prevention and treatment of cardiovascular disease, J. Gen. Intern. Med. 19 (2004) 380-389.

[17] R.S. Eidelman, D. Hollar, P.R. Hebert, G.A. Lamas, C.H. Hennekens, Randomized trials of vitamin $\mathrm{E}$ in the treatment and prevention of cardiovascular disease, Arch. Intern. Med. 164 (2004) 1552-1556.

[18] J. Stratton, M. Godwin, The effect of supplemental vitamins and minerals on the development of prostate cancer: a systematic review and meta-analysis, Fam. Pract. 28 (2011) 243-252.

[19] J.M. Gaziano, R.J. Glynn, W.G. Christen, T. Kurth, C. Belanger, J. MacFadyen, V. Bubes, J.E. Manson, H.D. Sesso, J.E. Buring, Vitamins E and C in the prevention of prostate and total cancer in men: the Physicians' Health Study II randomized controlled trial, J. Am. Med. Assoc. 301 (2009) 52-62.

[20] E.R. Miller III, R. Pastor-Barriuso, D. Dalal, R.A. Riemersma, L.J. Appel, E. Guallar, Meta-analysis: high-dosage vitamin E supplementation may increase all-cause mortality, Ann. Intern. Med. 142 (2005) 37-46 (Epub 2004 Nov 10).

[21] E.A. Klein, I.M. Thompson Jr., C.M. Tangen, J.J. Crowley, M.S. Lucia, P.J. Goodman, L.M. Minasian, L.G. Ford, H.L. Parnes, J.M. Gaziano, D.D. Karp, M.M. Lieber, P.J. Walther, L. Klotz, J.K. Parsons, J.L. Chin, A.K. Darke, S.M. Lippman, G.M. Goodman, F.L. Meyskens Jr., L.H. Baker, Vitamin E and the risk of prostate cancer: the Selenium and Vitamin E Cancer Prevention Trial (SELECT), J. Am. Med. Assoc. 306 (2011) 1556-1649.

[22] E.M. Burns, K.L. Tober, J.A. Riggenbach, D.F. Kusewitt, G.S. Young, T.M. Oberyszyn, Differential effects of topical vitamin E and C E Ferulic $\circledR^{\circledR}$ treatments on ultraviolet light B-induced cutaneous tumor development in Skh-1 mice, PLoS One 8 (2013), e63809.

[23] C. Cohen, J.F. Cardoso, S.B. Garcia, H. Vannucchi, Vitamin E supplementation in chemical colorectal carcinogenesis: a two-edged knife, Nutrients 6 (2014) 3214-3229.

[24] Q.J. Wu, Y.B. Xiang, G. Yang, H.L. Li, Q. Lan, Y.T. Gao, W. Zheng, X.O. Shu, J.H. Fowke Vitamin $\mathrm{E}$ intake and the lung cancer risk among female nonsmokers: a report from the Shanghai Women's Health Study, Int. J. Cancer 136 (2015) 610-617.

[25] R.L. Bailey, V.L. Fulgoni III, D.R. Keast, J.T. Dwyer, Dietary supplement use is associated with higher intakes of minerals from food sources, Am. J. Clin. Nutr. 94 (2011) 1376-1381.

[26] L. Rowe, E.D. Wills, The effect of dietary lipids and vitamin E on lipid peroxide formation, cytochrome P-450 and oxidative demethylation in the endoplasmic reticulum, Biochem. Pharmacol. 25 (1976) 175-179.

[27] M. Murray, In vitro and in vivo studies of the effect of vitamin E on microsomal cytochrome P450 in rat liver, Biochem. Pharmacol. 42 (1991) 1-7.

[28] Y.A. Sidorova, E.V. Ivanova, A.Y. Grishanova, V.V. Lyakhovich, Dose-dependent effect of alpha-tocopherol on activity of xenobiotic metabolizing enzymes in rat liver, Bull. Exp. Biol. Med. 136 (2003) 38-41.

[29] M. Paolini, L. Pozzetti, G.F. Pedulli, M. Cipollone, R. Mesirca, G. Cantelli-Forti, Paramagnetic resonance in detecting carcinogenic risk from cytochrome P450 overexpression, J. Investig. Med. 44 (1996) 470-473.

[30] S. Puntarulo, A.I. Caderbaum, Production of reactive oxygen species by microsomes enriched in specific human cytochrome P450 enzymes, Free Radic. Biol. Med. 24 (1998) 1324-1330

[31] A. Sapone, D. Canistro, S. Melega, R. Moles, F. Vivarelli, M. Paolini, On enzyme-based anticancer molecular dietary manipulations, J. Biomed. Biotechnol. 2012 (2012) 1-7.

[32] Y. Wang, G. Millonig, J. Nair, E. Patsenker, F. Stickel, S. Mueller, H. Bartsch, H.K. Seitz, Ethanol-induced cytochrome P4502E1 causes carcinogenic etheno-DNA lesions in alcoholic liver disease, Hepatology 50 (2009) 453-461.

[33] C. Bauer, C. Corsi, M. Paolini, Stability of microsomal monooxygenases in murine liver S9 fractions derived from phenobarbital and beta-naphthoflavone induced animals under various long-term conditions of storage, Teratog. Carcinog. Mutagen. 14 (1995) 13-22.

[34] O.H. Lowry, H.J. Rosenbrough, A.L. Farr, R.J. Randall, Protein measurement with folin phenol reagent, J. Biol. Chem. 193 (1951) 265-275.

[35] Y.L. Bailey, Techniques in Protein Chemistry, Elsevier, Amsterdam, 1967. 
[36] T. Omura, R. Sato, The carbon monoxide-binding pigment of liver microsomes I. Evidences for its hemoprotein nature, J. Biol. Chem. 239 (1964) 2370-2385.

[37] D. Canistro, J. Barillari, S. Melega, A. Sapone, R. Iori, E. Speroni, M. Paolini, Black cabbage seed extract affects rat Cyp-mediated biotransformation: organ and sex related differences, Food Chem. Toxicol. 50 (2012) 2612-2622.

[38] M. Bruce, Microsomal NADPH cytochrome c-reductase, Methods Enzymol. 10 (1967) 551-557.

[39] P. Mazel, Experiments illustrating drug metabolism in vitro, in: B.N. LaDu, H.G. Mandel, E.L. Way (Eds.), Fundamentals of Drug Metabolism and Drug Disposition, The Williams \& Wilkins Company, Baltimore MD 1971, pp. 546-555.

[40] T. Nash, Colorimetric estimation of formaldehyde by means of Hantzsch reaction, Biochem. J. 55 (1953) 416-421.

[41] L.A. Reinke, M.L. Mayer, p-Nitrophenol hydroxylation. A microsomal oxidation which is highly inducible by ethanol, Drug Metab. Dispos. 13 (1985) 548-552.

[42] R.A. Lubet, R.T. Mayer, J.W. Cameron, R.W. Nims, M.D. Burke, T. Wolff, pentoxyresorufin: a rapid and sensitive assay for measuring induction of cytochrome(s) P-450 by phenobarbital and other xenobiotics in the rat, Arch. Biochem. Biophys. 238 (1985) 43-48.

[43] M.D. Burke, S. Thompson, C.R. Elcombe, J. Halpert, T. Haaparanta, R.T. Mayer, Ethoxy, pentoxy- and benzyloxyphenoxazones and homologues: a series of substrates to distinguish between different induced cytochromes P-450, Biochem. Pharmacol. 34 (1985) 3337-3345.

[44] A. Aitio, A simple and sensitive assay of 7-ethoxycoumarin deethylation, Anal. Biochem. 85 (1978) 488-491.

[45] W.H. Habig, M.J. Pabst, W.B. Jakoby, Glutathione S-transferase AA from rat liver, J. Biol. Chem. 249 (1974) 7130-7139.

[46] D. Canistro, C.D. Croce, R. Iori, J. Barillari, G. Bronzetti, G. Poi, M. Cini, L. Caltavuturo, P. Perocco, M. Paolini, Genetic and metabolic effects of gluconasturtiin, a glucosinolate derived from cruciferae, Mutat. Res. 545 (2004) 23-35.

[47] J. Barillari, R. Iori, M. Broccoli, L. Pozzetti, D. Canistro, A. Sapone, B. Bonamassa, G.L. Biagi, M. Paolini, Glucoraphasatin and glucoraphenin, a redox pair of glucosinolates of brassicaceae, differently affect metabolizing enzymes in rats, J. Agric. Food Chem. 55 (2007) 5505-5511.

[48] P.I. Mackenzie, O. Hänninen, A sensitive kinetic assay for UDPglucuronosyltransferase using 1-naphthol as substrate, Anal. Biochem. 109 (1980) 362-368.

49] C.R. Wheeler, J.A. Salzman, N.M. Elsayed, S.T Omaye, D.W Korte Jr Automate assays for superoxide dismutase, catalase, glutathione peroxidase, and glutathione reductase activity, Anal. Biochem. 184 (1990) 193-199.

[50] L. Ernster, L. Danielson, M. Junggren, DT diaphorase. I. Purification from the soluble fraction of rat-liver cytoplasm, and properties, Biochim. Biophys. Acta 58 (1962) $171-188$.

[51] L. Valgimigli, G.F. Pedulli, M. Paolini, Measurement of oxidative stress by EPR radical-probe technique, Free Radic. Biol. Med. 31 (2001) 708-716.

[52] L. Valgimigli, M. Valgimigli, S. Gaiani, G.F. Pedulli, L. Bolondi, Measurement of oxidative stress in human liver by EPR spin-probe technique, Free Radic. Res. 33 (2000) 167-178.

[53] M. Valgimigli, M. Valgimigli, D. Trerè, S. Gaiani, G.F. Pedulli, L. Gramantieri, L Bolondi, Oxidative stress EPR measurement in human liver by radical-probe technique. Correlation with etiology, histology and cell proliferation, Free Radic. Res. 36 (2002) 939-948.

[54] M. Paolini, L. Valgimigli, E. Marchesi, S. Trespidi, G.F. Pedulli, Taking EPR “snapshots” of the oxidative stress status in human blood, Free Radic. Res. 37 (2003) 503-508.

[55] P. Box, W.G. Hunter, Statistics for Experiments, Wiley, New York, 1978.

[56] M.J. Grahama, B.G. Lake, Induction of drug metabolism: species differences and toxicological relevance, Toxicology 2008 (254) (2008) 184-191.
[57] A. Bast, Is formation of reactive oxygen by cytochrome $\mathrm{P} 450$ perilous and predictable? Trends Pharmacol. Sci. 7 (1986) 226-227.

[58] M. Paolini, L. Pozzetti, G.F. Pedulli, M. Cipollone, R. Mesirca, G. Cantelli-Forti, Paramagnetic resonance in detecting carcinogenic risk from cytochrome P450 overexpression, J. Investig. Med. 44 (1996) 470-473.

[59] C. Rodriguez-Antona, A. Gomez, M. Karlgren, S.C. Sim, M. Ingelman-Sundberg, Molecular genetics and epigenetics of the cytochrome P450 gene family and its relevance for cancer risk and treatment, Hum. Genet. 127 (2010) 1-17.

[60] D.W. Nebert, Identification of genetic differences in drug metabolism: prediction of individual risk of toxicity or cancer, Hepatology 14 (1991) 398-401.

[61] C.C. Mcllwain, D.M. Townsend, K.D. Tew, Glutathione S-transferase polymorphisms: cancer incidence and therapy, Oncogene 25 (2006) 1639-1648.

[62] K.J. Wolfe, J.K. Wickliffe, C.E. Hill, M. Paolini, M.M. Ammenheuser, S.Z. AbdelRahman, Single nucleotide polymorphisms of the DNA repair gene XPD/ERCC2 alter mRNA expression, Pharmacogenet. Genomics 17 (2007) 897-905.

[63] T.N. Sergentanis, K.P. Economopoulos, GSTT1 and GSTP1 polymorphisms and breast cancer risk: a meta-analysis, Breast Cancer Res. Treat. 121 (2010) 195-202.

[64] U.M. Zanger, M. Schwab, Cytochrome P450 enzymes in drug metabolism: regulation of gene expression, enzyme activities, and impact of genetic variation, Pharmacol. Ther. 138 (2013) (Epub 2013 Jan 16).

[65] N.J. Hodges, R.M. Green, J.K. Chipman, M. Graham, Induction of DNA strand breaks and oxidative stress in HeLa cells by ethanol is dependent on CYP2E1 expression, Mutagenesis 22 (2007) 189-194.

[66] A. León-Buitimea, L. Rodríguez-Fragoso, F.T. Lauer, H. Bowles, T.A. Thompson, S.W. Burchiel, Ethanol-induced oxidative stress is associated with EGF receptor phosphorylation in MCF-10A cells overexpressing CYP2E1, Toxicol. Lett. 209 (2012) 161-165.

[67] M.E. Elsherbiny, D.R. Brocks, The ability of polycyclic aromatic hydrocarbons to alter physiological factors underlying drug disposition, Drug Metab. Rev. 43 (2011) 457-475.

[68] W. Huang, J. Zhang, M. Wahington, J. Liu, J.M. Parant, G. Lozano, D.D. Moore, Xenobiotic stress induces hepatomegaly and liver tumors via the nuclear receptor constitutive androstane receptor, Mol. Endocrinol. 19 (2005) 1646-1653.

[69] P.A. Cerutti, Prooxidant states and tumor promotion, Science 227 (1985) 375-381.

[70] J.E. Klaunig, L.M. Kamendulis, The role of oxidative stress in carcinogenesis, Annu. Rev. Pharmacol. Toxicol. 44 (2004) 239-267.

[71] J.R. Marshall, Beta-carotene: a miss for epidemiology, J. Natl. Cancer Inst. 91 (1999) 2068-2069.

[72] I.M. Lee, N.R. Cook, J.E. Manson, J.E. Buring, C.H. Hennekens, Beta-carotene supplementation and incidence of cancer and cardiovascular disease: the Women's Health Study, J. Natl. Cancer Inst. 91 (1999) 2102-2106.

[73] H. Vainio, Chemoprevention of cancer: lessons to be learned from beta-carotene trials, Toxicol. Lett. 112 (2000) 513-517.

[74] M. Paolini, G. Cantelli-Forti, P. Perocco, G.F. Pedulli, S.Z. Abdel-Rahman, M.S. Legator, Co-carcinogenic effect of beta-carotene, Nature 398 (1999) 760-761.

[75] B. Halliwell, The antioxidant paradox, Lancet 355 (2000) 1179-1180.

[76] J.M. Gutteridge, B. Halliwell, Antioxidants: Molecules, medicines, and myths, Biochem. Biophys. Res. Commun. 393 (2010) 561-564.

[77] R.L. Bailey, J.J. Gahche, P.E. Miller, P.R. Thomas, J.T. Dwyer, Why US adults use dietary supplements, JAMA Intern. Med. 173 (2013) 355-361.

[78] M. Wenner Moyer, Nutrition: vitamins on trial, Nature 510 (2014) 462-464.

[79] B. Halliwell, The antioxidant paradox: less paradoxical now? Br. J. Clin. Pharmacol. 75 (2013) 637-644

[80] J.D. Potter, The failure of cancer chemoprevention, Carcinogenesis 35 (2014) 974-982. 